\title{
HISTORICAL MAPS IN GIS
}

David Rumsey and Meredith Williams

M

OsT historical GIS would be impossible without historical testify. Maps mation that is fundamental to reconstructing past places, whether town, region, or nation. Historical maps often hold information retained by no other written source, such as place-names, boundaries, and physical features that have been modified or erased by modern development. Historical maps capture the attitudes of those who made them and represent worldviews of their time. A map's degree of accuracy tells us much about the state of technology and scientific understanding at the time of its creation. By incorporating information from historical maps, scholars doing historical GIS are stimulating new interest in these rich sources that have much to offer historical scholarship and teaching. At the same time, the maps themselves challenge GIS users to understand the geographic principles of cartography, particularly scale and projection. We have addressed these challenges in order to examine the value of including nineteenth- and early twentiethcentury paper maps in GIS. 1

One can use digital renditions of historical maps to study historical landscapes, the 
Figure I. WHEeler SURVEY MAP OF Yosemite VAlley, I883

The government-Funded Wheeler SURVEY PRODUCED ONE OF THE FIRST ACCUrate maps of Yosemite Valley. The CARTOGRAPHERS WHO DREW THE MAP USED HACHURING (A FORM OF SHADING) TO SUGGEST THE DEPTH OF THE CANYON AND THE RIVER VALLEYS LEADING TO IT. maps themselves, and how places changed over time. GIS is breathing new life into historical maps by freeing them from the static confines of their original print form. It is also enabling a new level of understanding. Traditionally, people read and analyzed maps using a critical eye and a priori knowledge. Comparison of two or more maps was possible, but the conclusions were only as reliable as the reader's visual acuity and interpretive skill. The same limits applied to cartography, the making of maps. Cartographers traditionally made maps by gathering information from published maps or field surveys. The maps they produced were often marvelous acts of interpretation. Consider the Wheeler Survey, which mapped territory west of

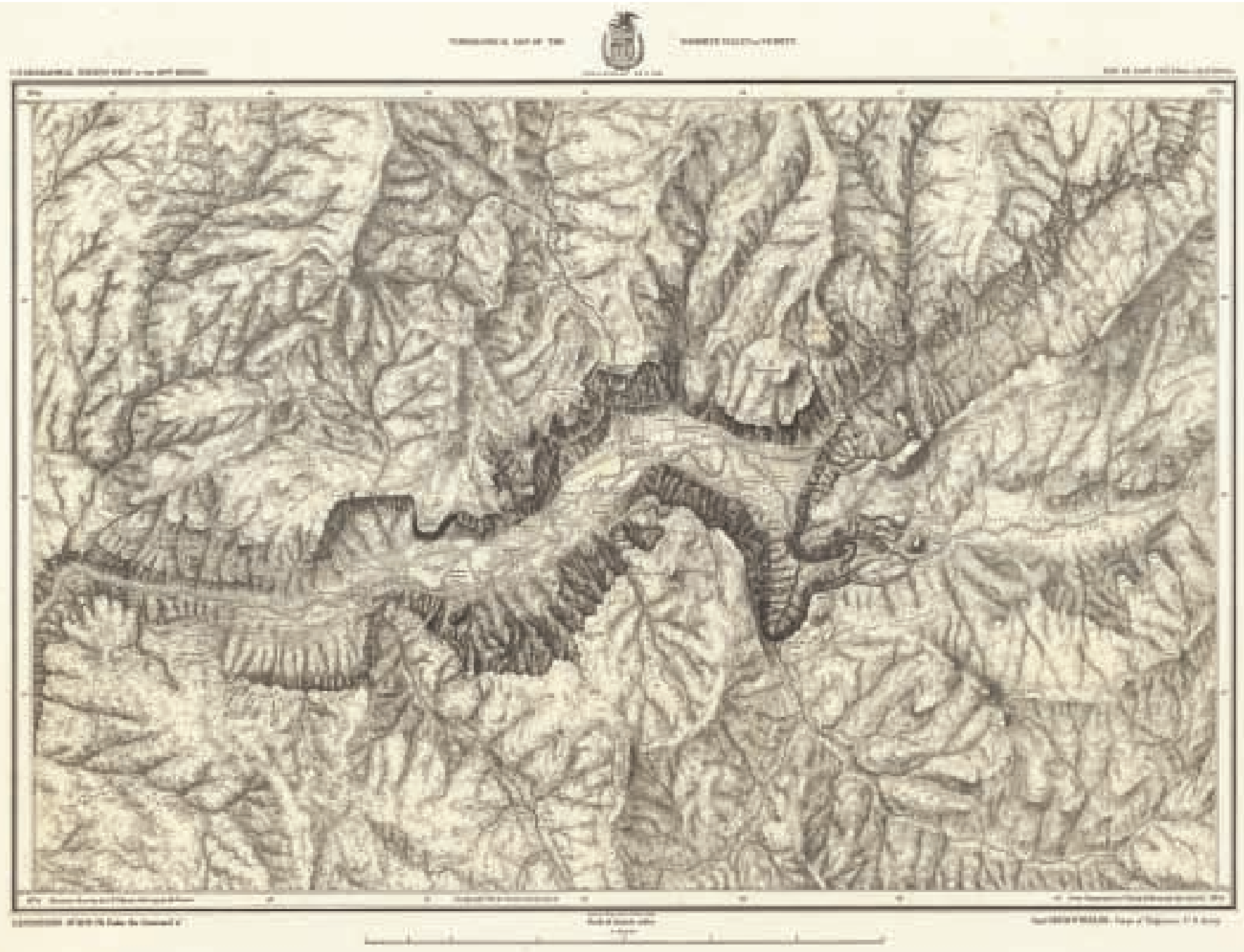


the Iooth meridian in a series of geographical expeditions beginning in $187 \mathrm{I}$. George M. Wheeler and his associates carried heavy plane tables, surveyor's instruments, and large-format cameras by wagon and mule across mountains, canyons, and deserts. Their survey points were highly accurate for the time, but the renderings of the topography that linked those points in a continuous landscape were as much art as science (figure I). When their map is converted into digital form, it can be manipulated and combined with other spatial data, such as digital elevation models (figure 2). The three-dimensional landscape is more immediately recognizable. It gives us the feel of standing next to the cartographer as he gazed over Yosemite Valley.

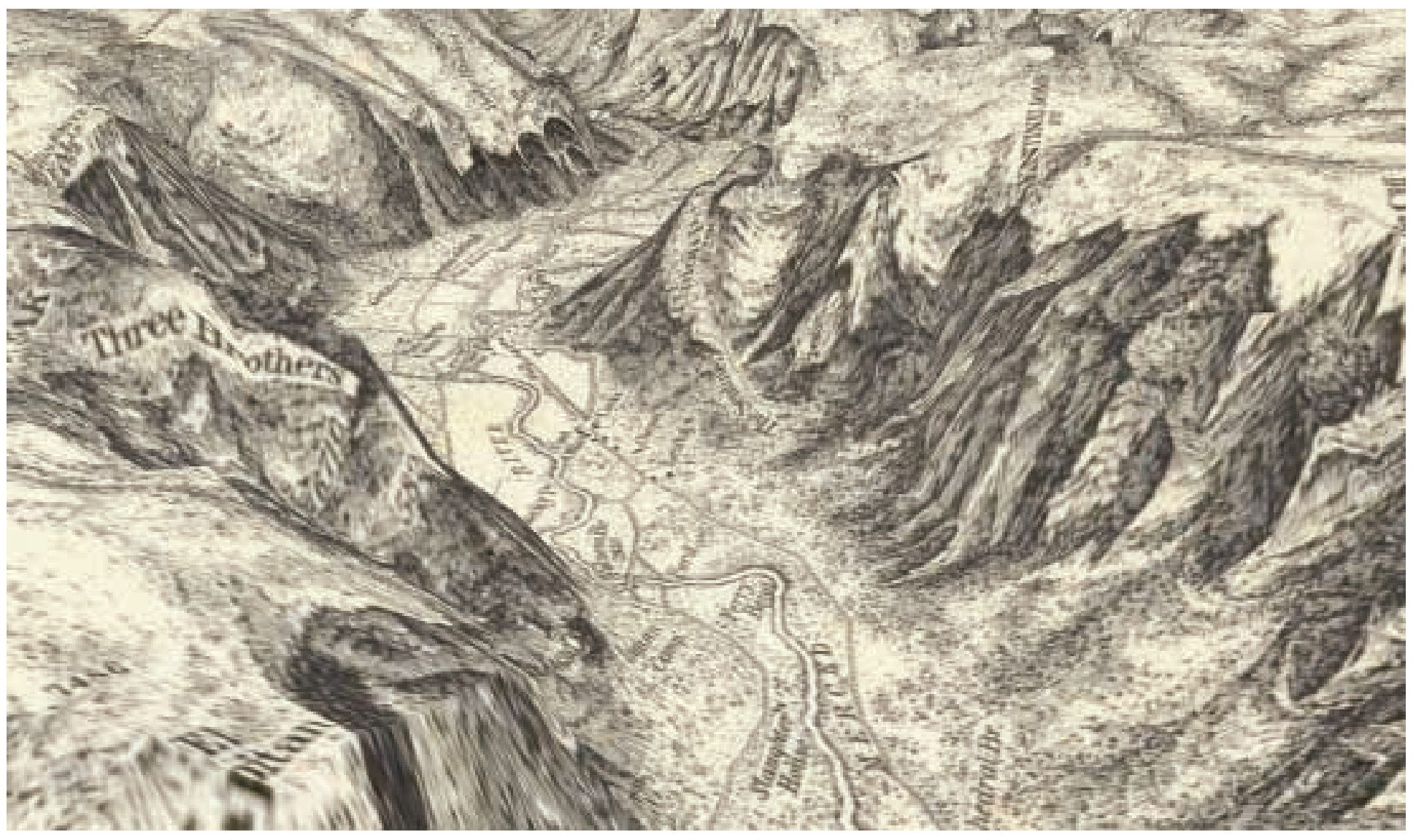

Figure 2. Wheeler's Yosemite Valley in 3-D

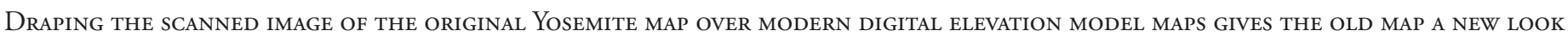
AND IMMEDiaCy. THE SIMULATED DEPTH OF THE 3-D TERRAIN MODEL COMPLEMENTS THE BEAUTIFUl HACHURING OF THE I883 MAP. IN THIS MAP WE USED A VERTICAL EXAGGERATION FACTOR OF I.5. 


\section{Figure 3. Chicago in I868} AND 1997

HOT LINKS CONNECTING HISTORICAL CITY PLANS TO PRESENT-DAY MAPS GIVE STUDENTS EASY ACCESS TO VISUAL COMparisons. Rufus Blanchard's Guide Map of Chicago (I868) SHOWS THE CITY'S CHARACTERISTIC GRID AND CROSSCUTTING DIAGONAL ARTERIES, LITTLE CHANGED IN A RECENT ARCVIEW ${ }^{\circledR}$ STreetMaP ${ }^{\text {TM }}$. The Dimensions of THE CITY, HOWEVER, HAVE CHANGED ENORMOUSLY.
More importantly for the aims of historical research, information that was difficult to perceive in the historical map is now accessible for our own investigation. We can now measure elevation, distance, and area, and rotate the image to place ourselves at different viewpoints.

Ordinarily, the first step in preparing a paper map for use in GIS is scanning it. For this purpose, it is best to capture map images at a very high resolution. ${ }^{2}$ If one's main purpose is to study maps as historical documents, scanning may be all the manipulation required. Scanned maps can be easily incorporated into a GIS as graphic images. Connected by hot links to particular features in a GIS layer, historical maps can be opened to compare present and past configurations of a given place or landscape (fgure 3).

Integrating historical maps in GIS to analyze the spatial information they contain, or to layer them with other spatial data, requires that the maps be georeferenced. That is, selected control points on a scan of the original map must be aligned with their actual geographical location, either by assigning geographical coordinates to each point, or by linking each point to its equivalent on a modern,

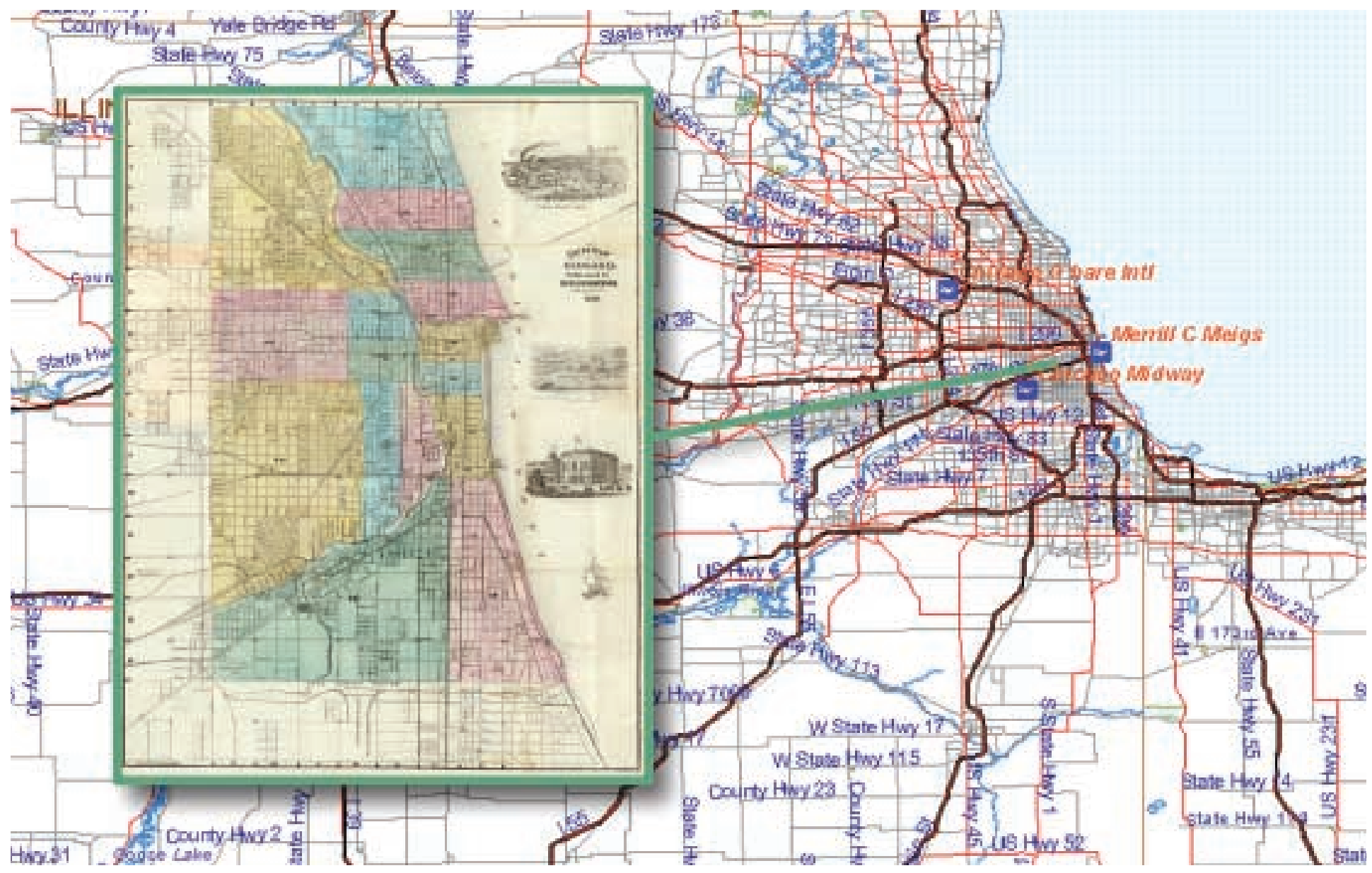


accurate digital map. Once the control points are in place, one applies mathematical algorithms to warp the original map image to fit the chosen map projection as nearly as possible. Further adjustments can be done manually to try to find the best fit for all parts of the original map. The process is sometimes called rubber sheeting because it stretches and shrinks the map image like a thin sheet of rubber being pulled to fit a particular form. Figure 4, for example, is a scanned detail of the Wheeler Survey's I882 map of New Mexico that we georeferenced and then layered with point data marking the location of
Jesuit missions. 3 Placing the missions in their physical context helps one see the geographical logic of their location and infer their relationship with regional patterns of commerce and transportation that developed between their founding in the late seventeenth century and their decline at the end of the nineteenth.

It is almost impossible to perfectly align an old map to modern coordinate systems because mapping methods before the age of aerial photography often only very imprecisely represented scale, angle, distance, and direction. For most GIS projects, the value of the historical information
Figure 4. Adding features to a HISTORICAL MAP

THIS I882 GEOREFERENCED MAP FROM the Wheeler Survey shows the Rio Grande Valley just north of Santa Fe. The cartographer's HACHURES MARK THE STEEP PLATEAUS AND MESAS OF THE RUGGED REGION WHERE FRANCISCAN PRIESTS ESTABLISHED MISSIONS AMONG THE NATIVE INDIAN PEOPLE AS EARLY AS I692. THE RED POINTS REPRESENT A LAYER OF DATABASE INFORMATION ABOUT THE MISSIONS. BY CLICKING ON THE POINTS, USERS CAN BRING UP HISTORICAL DATA ABOUT EACH SITE.

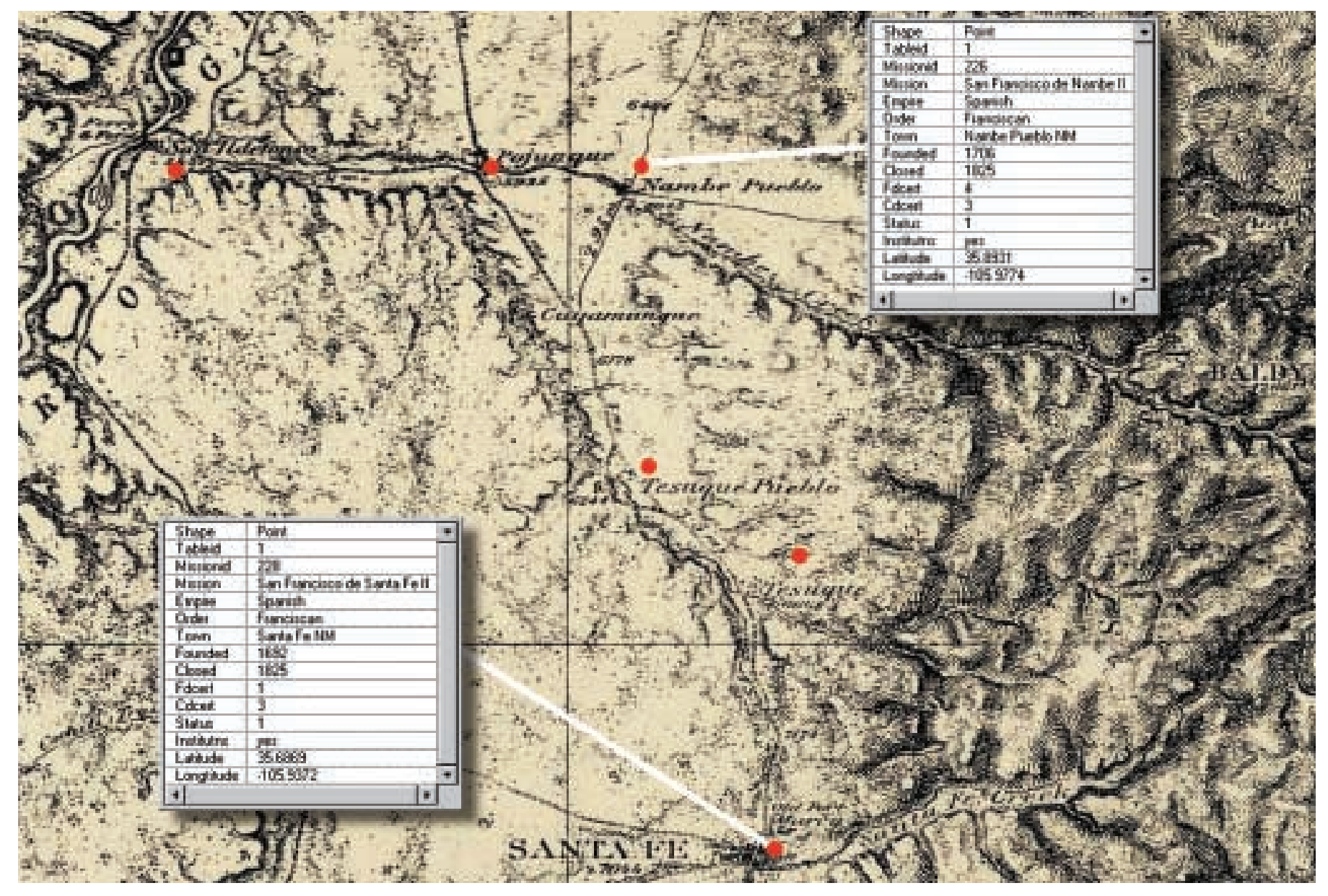


on paper maps more than compensates for the residual error in their georeferenced versions. What one should keep in mind is that georeferencing does not necessarily improve a historical map or make it more accurate. In the course of changing the original map to make it amenable to digital integration, georeferencing changes lines and shapes, the distance between objects, the map's aesthetics, and its value as a cultural artifact. One gains knowledge of the original while processing it for inclusion in GIS, but one also loses something if the original map is not represented for comparison with its actual size, proportions, and qualities. Ideally, researchers should include both the warped map and the scanned image of the original map in a GIS project or publication.

The impossibility of aligning historical maps perfectly with modern maps can itself yield historical information. During their exploration of the Louisiana Purchase, Meriwether Lewis and William Clark made notations of longitude and latitude, which they later used in drawing the monumental map of their expedition (figure 5). To bring this map into GIS, we began by estimating the projection used for Lewis and Clark's rendering. Their map appears to be on a conic projection, since the lines of latitude are curved and those for longitude converge. A common conic projection for maps of the continental United States is Albers Equal-Area, so we used a vector layer in this projection as a base for georeferencing the exploration map. Control points were taken by assigning geographical coordinates to reference points, such as the explorer's longitude and latitude marks and major river junctions. By then overlaying modern highways (red) and state boundaries (brown), one can gauge Lewis and Clark's errors in measurement and estimation.

Small-scale historical maps like Lewis and Clark's are prone to greater error than large-scale maps. ${ }^{4} \mathrm{~A}$ large area of the earth's surface, like the continental United States, is harder to depict on a flat surface than a small area such as a town. 5 Largescale maps are often more easily and accurately converted for use in GIS because they tend to have less egregious geographical errors. Maps drawn at a large scale may also have more unique local data to contribute, such as information on land ownership, the location of buildings, paths, and streams, and so forth.

Large-scale city maps can be wonderful sources for urban history, and adding one to a GIS can greatly increase its utility. Many American cities were mapped repeatedly and in great detail in the nineteenth 


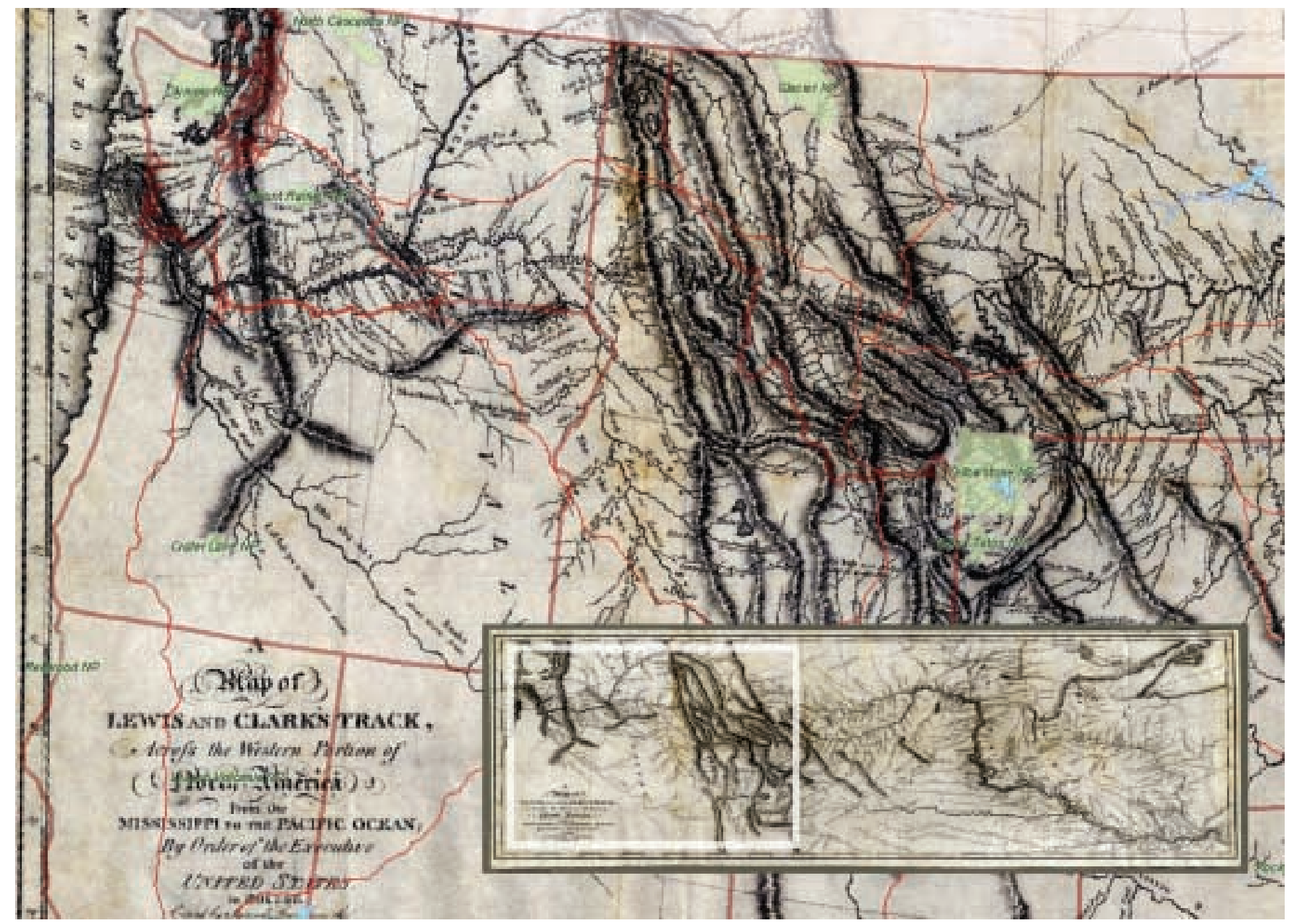

Figure 5. Gauging the accuracy of Lewis and Clark's map

A Map of Lewis and Clark's Track, Across the Western Portion of North America (i8i4, inset, lower right) combines the explorers'

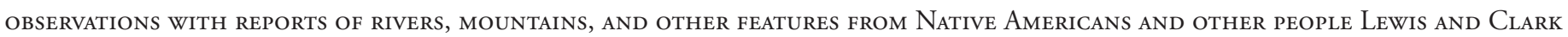
ENCOUNTERED ON THEIR THREE-YEAR JOURNEY. THE ORIGINAL MAP IS 7 O CM WIDE. GEOREFERENCING THE MAP REVEALS SIGNIFICANT DiSTORTION IN THE POSITION OF THE WESTERN COAST (NOTE THE BROWN OUTLINE OF THE TRUE WESTERN COAST ON THE LEFT SIDE OF THE FIGURE). THIS WAS LIKELY DUE TO ERRORS IN DRAFTING OR PROJECTION OF THE ORIGINAL MAP. 
and twentieth centuries, none more so than New York. J. H. Colton's Topographical Map of the City and County of New-York (I836) and Matthew Dripps' Map of the City of New York (I852) provide unparalleled images of the built environment of America's leading nineteenth-century commercial city. These two unusually large maps are of differing scales. Colton's map, at a scale of I:I5,840, measures 29 by almost 70 inches. Dripps' huge map, nearly 88 inches long and 46 inches wide, shows lower Manhattan at the very large scale of I:3,450, approximately two inches to the city block. Although the physical size of the two maps made them difficult to scan, it was possible, and their large scales and precision made them relatively easy to georeference. Overlaying georeferenced historical maps allows one to combine maps of greatly differing sizes and scales, such as these, in the same coordinate space.

With the innovation of partially transparent raster layers in GIS, we were able to produce composite map images that suggest how the passage of time transformed the city (figure 6). Some changes became strikingly clear when we then overlaid a modern digital street map on the georeferenced Colton map (figure 7). For example, we could see that the Hudson Parkway and East River Drive, highways that run along the west and east sides of Manhattan, respectively, were built on landfill beginning at about $72 \mathrm{~d}$ Street. The original New York City reservoir, whose ghostly rectangular pools occupy the center of Central Park on the map detail, was moved north and given a more natural-seeming shape by the park's landscape architect, Frederick Law Olmsted. What was low-lying, swampy ground in the early I850s, on the upper East Side between 85 th and Io5th streets, was drained and filled later in the century to provide housing for the city's exploding population.

Visual overlay of this type is very useful in research and teaching. However, to query or measure spatial relationships between features, they must be lifted off historical maps and made into vector GIS layers. This is done by digitizing map features as points, lines, and areas. Because few archives provide access to a digitizing tablet, scholars often choose to have historical maps scanned. They can then digitize the maps directly on screen. Digitizing is far more time-consuming than georeferencing, but it adds tremendously to the amount of data available for use in GIS. By creating vector polygon features from the city blocks and building locations on Colton's New York City map, 

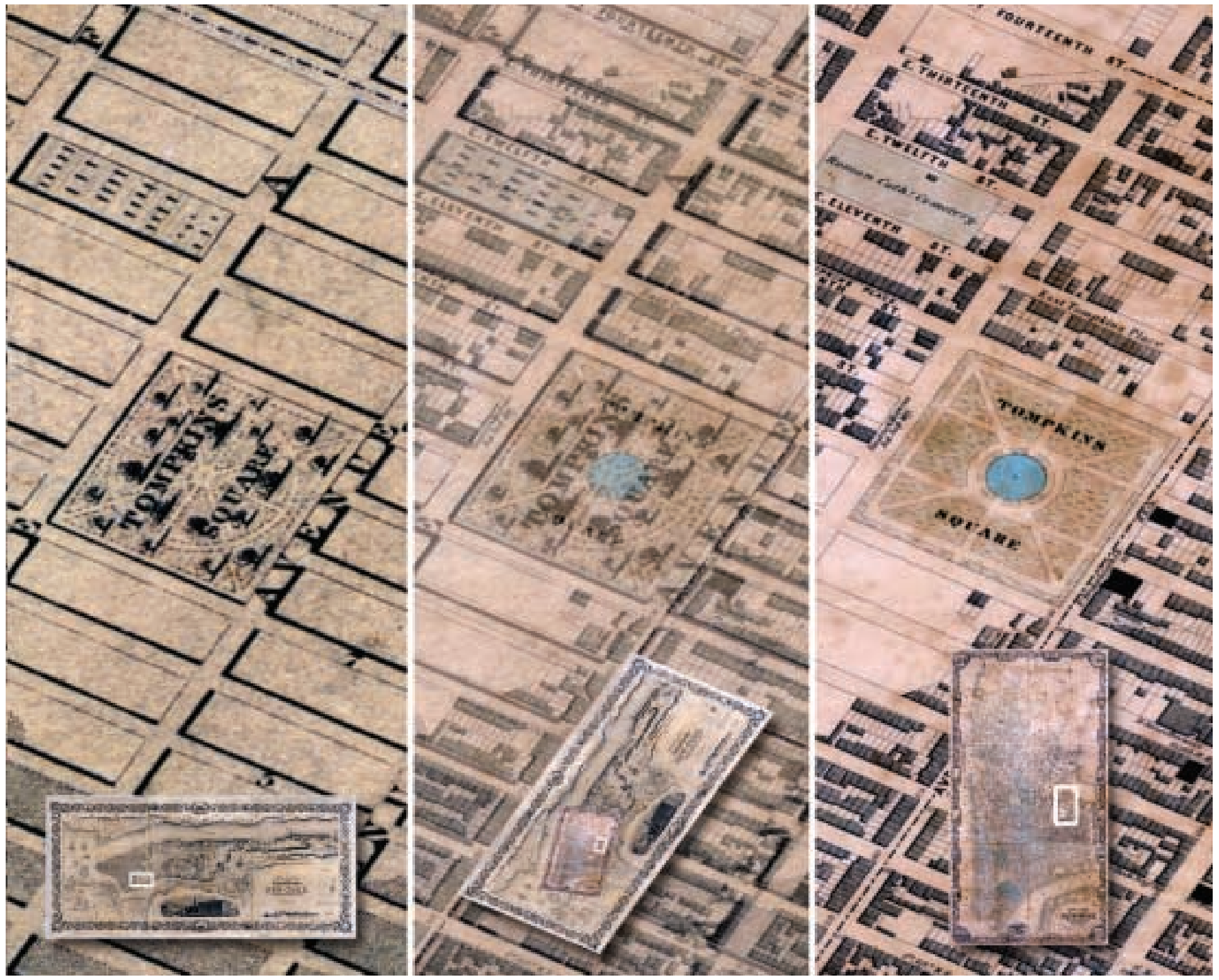

Figure 6. Urban deVelopment in New York City, I836-I852

In i836, the area around Tompkins SQuare in the East Village had few occupants but those buried in the Roman Catholic Cemetery, AS SEEN IN THE MAP ON THE LEFT. BY I852 (RIGHT MAP) THE NEIGHBORHOOD WAS FULL OF ROW HOUSES, BUSINESSES, TENEMENTS, AND BACK ALLEYS WHERE SERVANTS AND LOW-WAGE WORKERS LIVED. TOMPKINS SQUARE HAD ALSO BEEN TRANSFORMED FROM A COUNTRY PARK OF TREES AND ORNAMENTAL PATHS TO AN OPEN GREEN WITH A CENTRAL FOUNTAIN. A TRANSPARENT COMPOSITE OF THE TWO MAPS (CENTER IMAGE) MAKES COMPARISON EASIER. 


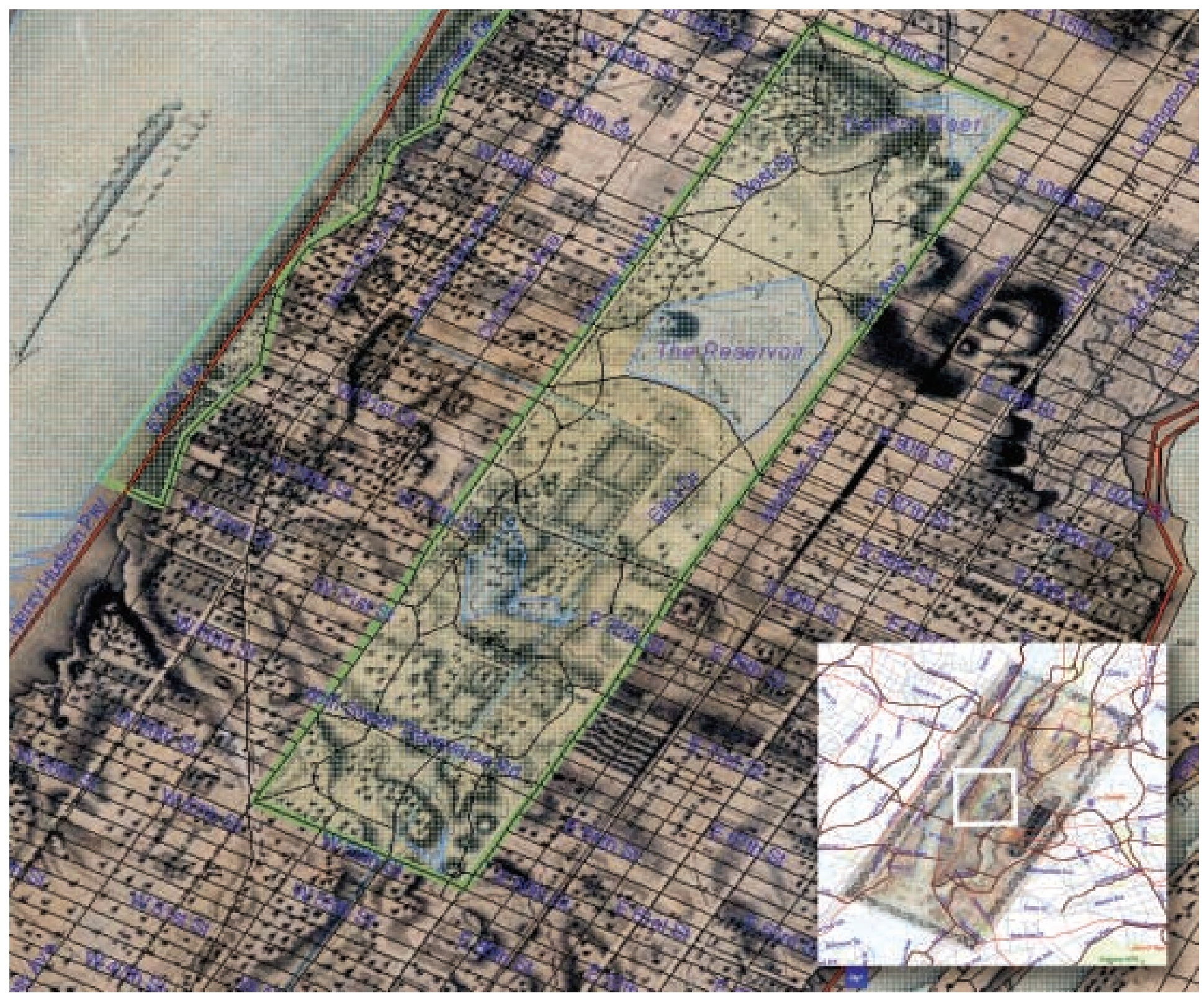

Figure 7. Comparing New York City in i836 and 1997

GIS ENABLES ONE TO COMPARE GEOREFERENCED HISTORICAL MAPS WITH MODERN MAPS BY OVERLAYING THEM. THIS IMAGE OVERLAYS A MODERN street map on Colton's map of the antebellum city. All of Manhattan was platted for development in i836, but above Times Square THE GRID HAD MORE TREES THAN PEOPLE. 
for example, we could join attribute data such as owner, land-use category, date of construction, structure type, and architectural style for each building. All lots could then be queried for ownership and classified as either private or public. Different colors could then be used to signify public and private lots. Total acreage could be calculated for each land category. Performing the same steps on a later map of the city and comparing the two sets of data would enable us to identify the changing patterns of public and private ownership and architectural style. The dynamics of urban change could be displayed through an animation of cartographic snapshots of New York's built environment.

In addition to illuminating urban history, historical maps can provide valuable information about environmental change. Today, satellites circle the earth recording daily changes on the planet's surface. Scientists study satellites' remotely sensed data to determine how human activity and natural phenomena interact. Historical maps make it possible to extend the examination of humans' environmental impact far back before the advent of satellite imagery. To explore changes in land use in southern California, we used GIS to combine the I88I Wheeler Survey thematic map of the area with a 1998 land-cover map from the California Gap Analysis Project (figure 8). The Wheeler map depicts a rural landscape scarcely touched by urbanization. It displays five land-use categories: agriculture, timber, grazing, arid/barren land, and chaparral, shown in pastel tints of yellow, green, and gray. The city of Los Angeles, with just eleven thousand people, sits at the base of the Santa Monica and San Gabriel mountains. We overlaid the 1998 data as a transparent polygon layer to examine the extent of the land-use changes. Wheeler's team would be surprised to see that today, urban development covers all but the highest, steepest peaks.

On a number of the historical maps we have discussed, shading or hachures (fine black lines) suggested elevation. Using GIS, one can simulate topography more dramatically and vividly by using digital elevation models, which are raster surfaces composed of longitude (x), latitude (y), and elevation $(\mathrm{z})$ coordinates. ${ }^{6}$ We already saw how draping the Wheeler Survey's Yosemite map over a digital elevation model enhanced the historical map's depiction of the landscape. Verisimilitude can be a powerful teaching tool when it helps students understand the physical character of a past place. When we displayed August Chevalier's I9I5 map of San Francisco over 


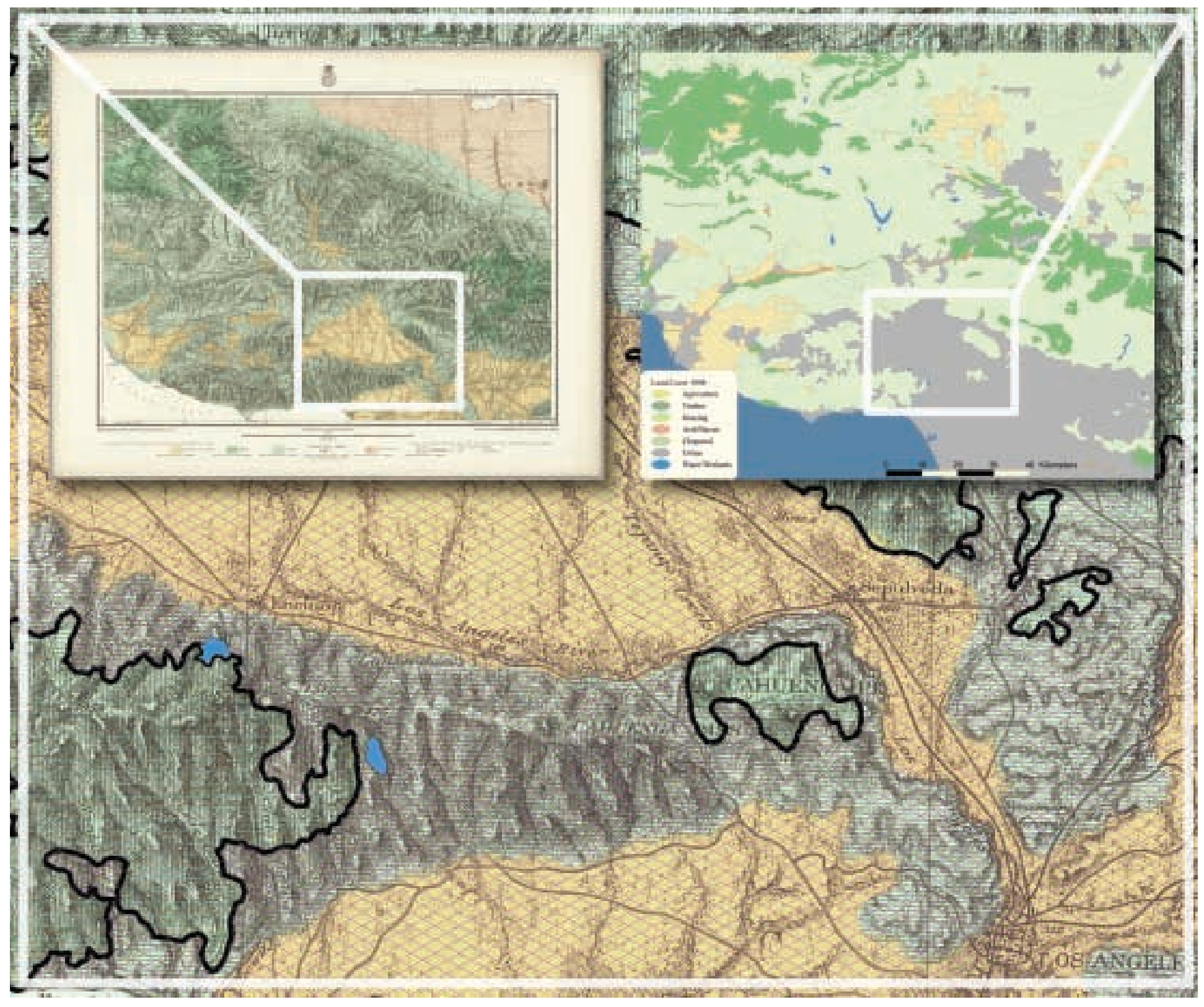

Figure 8. Los ANGeles THEN AND NOW

LOOKING BACK AND FORTH BETWEEN THE TWO UPPER MAPS GIVES ONE A SENSE OF HOW MUCH THE SOUTHERN CALIFORNIA LANDSCAPE HAS CHANGED.

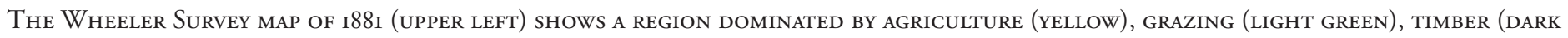
GREEN), AND ARID LAND (LIGHT BROWN). THE 1998 MAP (UPPER RIGHT) SHOWS A FLOOD OF URBAN DEVELOPMENT (GRAY) COVERING MOST OF THE FORTY-KILOMETER AREA OF THE LOS ANGeleS BASIN, OUTLINED IN WHITE. IN THE COMBINED MAP SHOWN AT A LARGER SCALE, URBAN DEVELOPMENT, SYMBOLIZED BY A RED DIAGONAL GRID, COVERS ALMOST ALL OF THE BASIN. 
a digital elevation model, the extreme topography of the city leapt to view (figure 9).

One can also use digital models to explore the terrain that lies beneath the oceans. We experimented with this idea using our digital rendering of the 1926 U.S. Coast Survey map of San Francisco Bay and the 1998 digital contour line map of the same area produced by the National Oceanic and Atmospheric Administration (NOAA). The 1926 map noted depth at hundreds of points around the bay. When we queried the same points on the 1998 map, we found that some elevations had changed significantly due to human activity. The north end of Treasure Island, for example, which lay beneath fourteen fathoms of seawater in 1926, was now above sea level; landfill more than tripled the island's dry surface area. To clearly display the bathymetry of the bay-that is, the shape and depth of the seafloor-we converted the NOAA contour map into a triangulated irregular network (TIN) layer.7 This created a detailed 3-D model of the bathymetry that we could then combine with the historical Coast Survey map (figures IO, II). Suddenly we could easily and vividly see the deep trench of
Figure 9. San Francisco in 3-D August Chevalier used shading to SUGGEST THE RUGGED TOPOGRAPHY OF San Francisco in igi5. Draping a geoREFERENCED VERSION OF HIS MAP OVER A DIGITAL ELEVATION MODEL MORE CLEARLY SHOWS THE RELATIVE HEIGHT OF EACH HILL, THE VALLEYS CUT BY STREAMS, AND THE DENSITY OF BUSINESS AND RESIDENTIAL DEVELOPMENT ON THE MOST LEVEL GROUND ALONG THE HARBOR. THE VERTICAL EXAGgERATION FACTOR IN THIS MAP IS I.5.

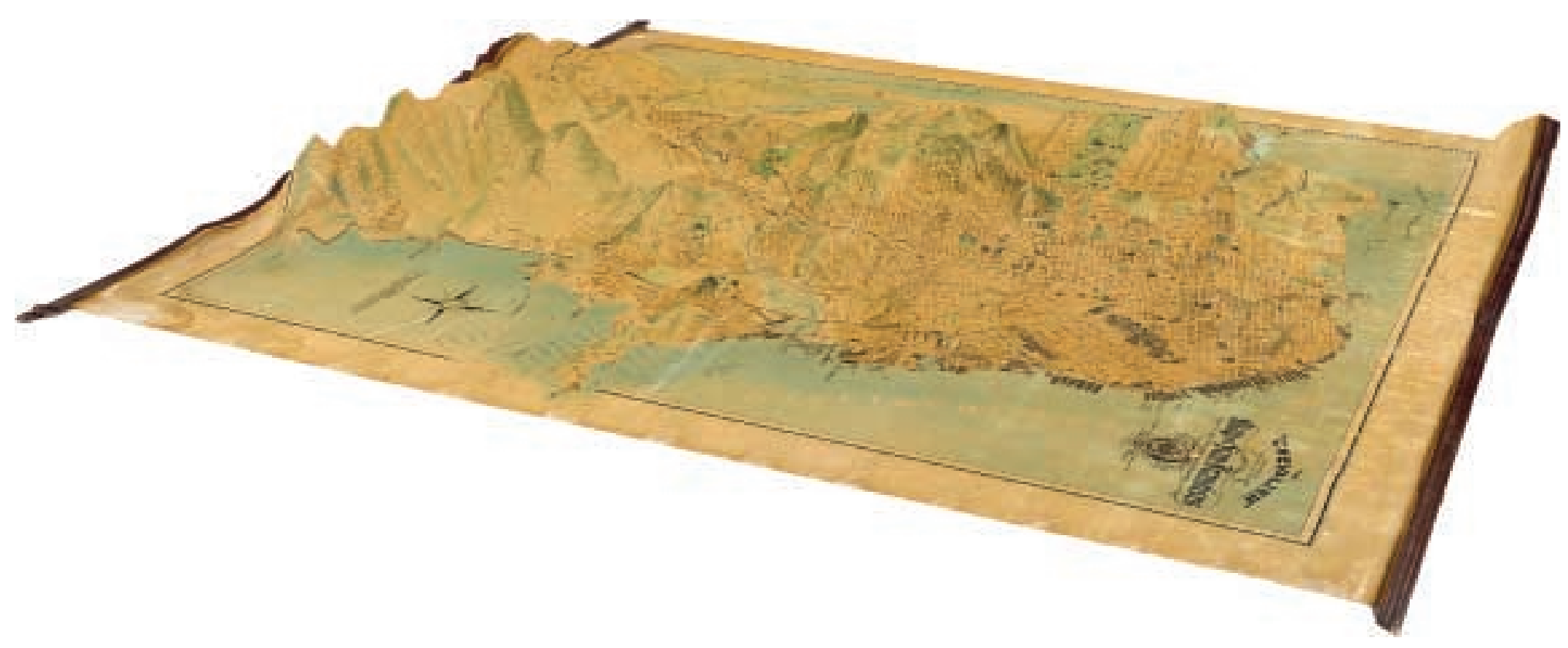




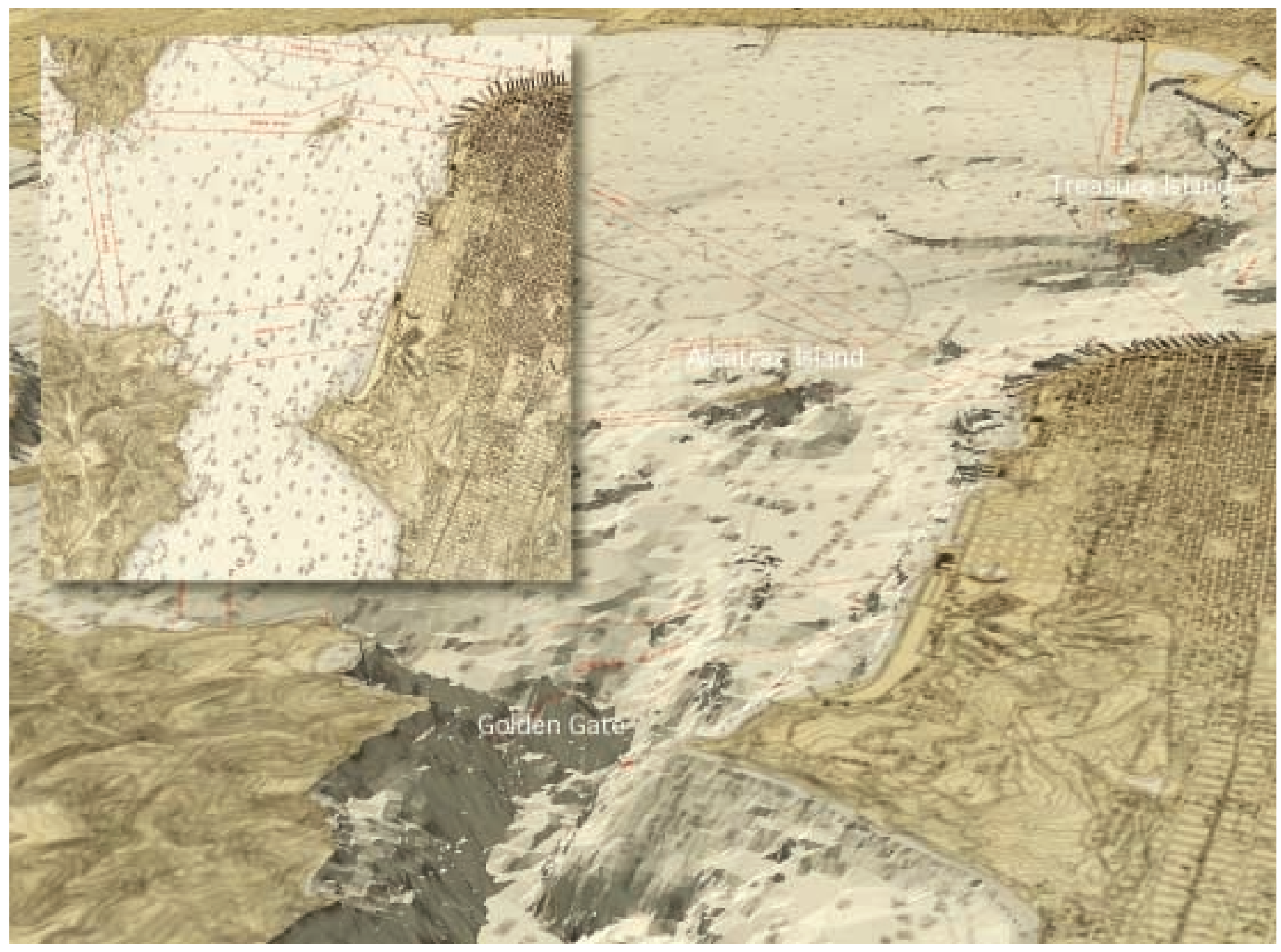

Figure io. The depths of San Francisco Bay

Adding Visual depth to the bay puts two historical icons of San Francisco into context: the Golden Gate Bridge, its Claim to be an ENGINEERING MARVEL NOW EVIDENT IN THE FOUR-HUNDRED-FOOT CHASM IT SPANS; AND THE TOP-SECURITY PRISON ON ALCATRAZ ISLAND, GUARDED BY DEEP WATERS AND SWIFT CURRENTS. BeCAUSE THE 3-D MODEL WAS BUILT FROM BATHYMETRY DATA ONLY, THE DRY LAND APPEARS FLAT. WE USED A VERTICAL EXAGGERATION FACTOR OF 7 TO BRING OUT DEPTH VARIATION IN THIS MAP AND FIGURE II. 


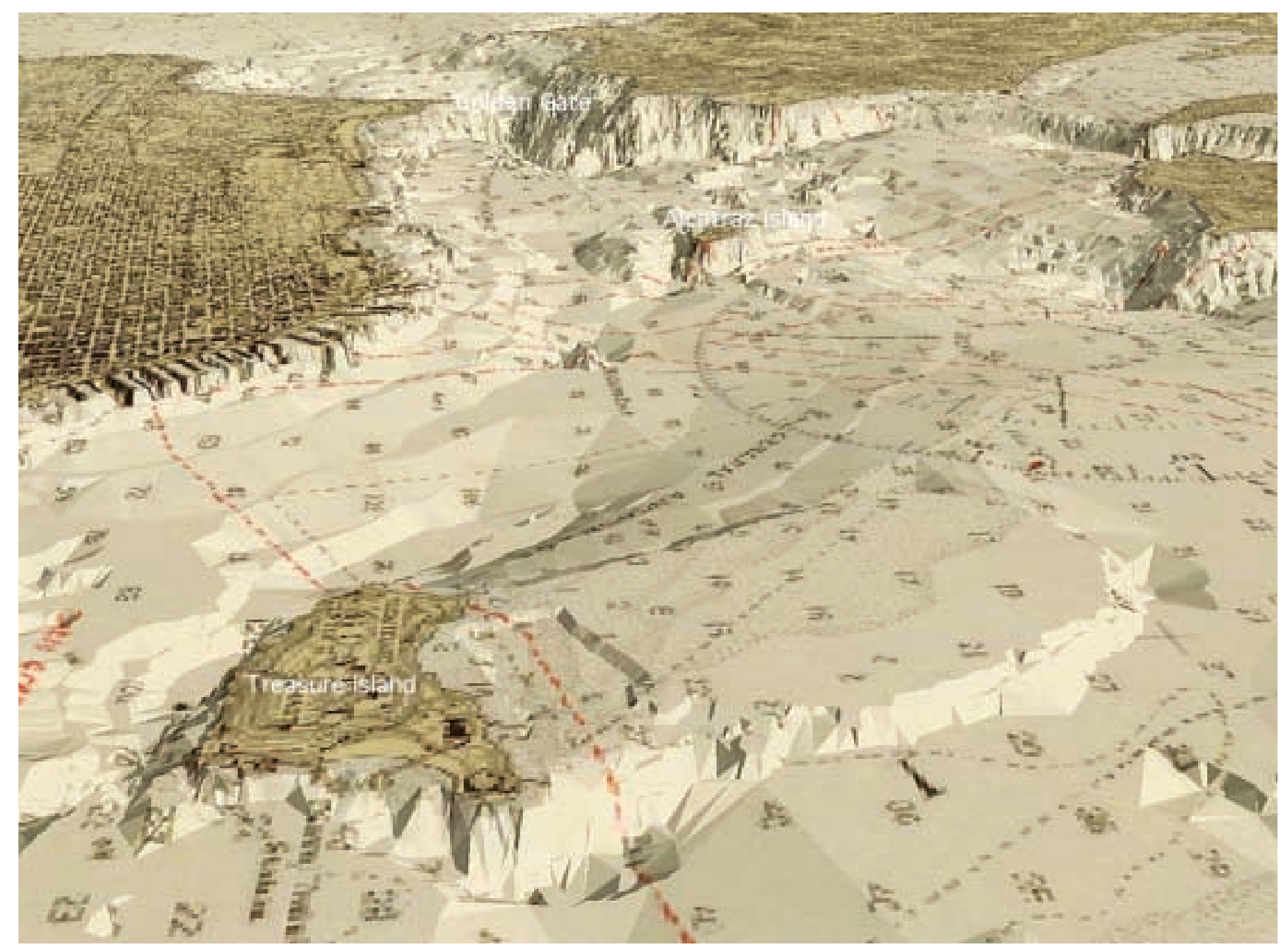

Figure iI. San Francisco Bay showing Treasure Island landfill

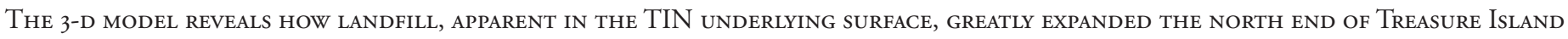
FOR THE 1939 WORLD'S FAIR. IN THE SAME AREA, MARKINGS FROM THE ORIGINAL SEA CHART, DRAWN THIRTEEN YEARS EARLIER, SHOW THE PREFILL DEPTHS OF FOURTEEN TO TWENTY-TWO FATHOMS. 
the Golden Gate Strait, the relative shallows of San Pablo Bay, and the chasm surrounding Alcatraz Island, site of the famous prison. The 3-D viewing software even allowed us to travel around the scene as if in a submarine.

To include historical maps in GIS for teaching and research, scholars will need access to high-quality scanners or prepared digital images. We envisage a time in the near future when thousands of historical map images, some already georeferenced and digitized as vector layers, will be available through shared networks and public-access Web sites. Recent improvements in GIS software are resolving the problems of storing everlarger spatial data sets by enabling users to access remotely stored data. The Library of Congress Geography and Map Division and a few other leading map collections in the United States and other countries have launched digital dissemination projects. From the Library of Congress Memory Web site, anyone can download map images and then zoom in to study their details on-screen as if with a powerful magnifying glass. The David Rumsey Historical Map Collection has scanned more than sixty-five hundred historical maps and made them available online. Rumsey will provide an increasing number of georeferenced versions in the next few years. Digital renderings of historical maps are also available through ESRI's Geography Network and the Electronic Cultural Atlas Initiative's Metadata Clearinghouse. Since the process of converting historical maps into GIS-compatible formats is time-consuming, resource intensive, and expensive, it is doubly important that the burden be shared and the resulting resources aggregated. Each digitized map will require excellent, standardized metadata to describe it and make it easy to retrieve.

Historical maps have a great deal to offer GIS, and GIS brings new techniques to the analysis and display of historical maps. As historical maps become more widely available and as GIS becomes more sophisticated, it is certain that scholars will combine the two in creative ways yet to be imagined. Cartographers of days past would have been pleased to know that centuries later a new mapping technology is stimulating new interest in their work. 


\section{Map sources}

All maps courtesy of the David Rumsey Historical Map Collection, www.davidrumsey.com.

Blanchard, Rufus, Guide Map of Chicago, 1868. Chicago: Rufus Blanchard. Size: $53 \mathrm{~cm} \times 4 \mathrm{I} \mathrm{cm}$. Scale: I:25,344.

Colton, J. H., Topographical Map of the City and County of New-York, I836. New York: J. H. Colton \& Co. Size: $74 \mathrm{~cm} \times 170 \mathrm{~cm}$. Scale: $1: 15,840$.

Chevalier, August, The "Chevalier" Commercial, Pictorial and Tourist Map of San Francisco, I9I5. San Francisco: Aug. Chevalier. Size: $160 \mathrm{~cm} \times 145 \mathrm{~cm}$. Scale: 1:9,600.

Dripps, Matthew, Map of the City of New York Extending Northward to Fiftieth St., I852. New York: M. Dripps. Size: $223 \mathrm{~cm} \times 117 \mathrm{~cm}$. Scale: $1: 3,450$.

Lewis, Meriwether, and William Clark, A Map of Lewis and Clark's Track, Across the Western Portion of North America, I8I4. Philadelphia: Bradford and Inskeep. Size: $30 \mathrm{~cm} \times 70 \mathrm{~cm}$. Scale: I:4,350,000.

United States Coast and Geodetic Survey, United States-West Coast. San Francisco Entrance, California, 1926. Washington, D.C.: U.S. Coast and Geodetic Survey. Size: $85 \mathrm{~cm} \times 105 \mathrm{~cm}$. Scale: I:40,000.

Wheeler, G. M, Land Classification Map of Part of S. W. California, Atlas Sheet No. 73 (C), I88I. Washington, D.C.: U.S. Government. Size: $45 \mathrm{~cm} \times 52 \mathrm{~cm}$. Scale: I:253,440.

Wheeler, G. M., North Central New Mexico, Atlas Sheet No. 69 (D), I876. Washington, D.C.: U.S. Government. Size: $45 \mathrm{~cm} \times 5 \mathrm{I} \mathrm{cm}$. Scale: I:253,440.

Wheeler, G. M., Topographical Map of the Yosemite Valley and Vicinity, I883. Washington, D.C.: U.S. Government. Size: $43 \mathrm{~cm} \times 55 \mathrm{~cm}$. Scale: I:42,240.

\section{Software and hardware}

ArcView 3.2, ArcView 8.I, Adobe ${ }^{\circledR}$ Photoshop $^{\circledR}$ 5.5, Luna Imaging, Inc.'s Insight ${ }^{\circledR}$, MrSID $^{\mathrm{TM}}$ image compression software by LizardTech ${ }^{\circledR}$, PhaseOne image-capture software. PhaseOne PowerPhase and PowerPhase FX $4 \times 5$ digital scanning camera back, Sinar $X_{4} \times 5$ view cameras with Rodenstock lenses, Kaiser RePro copy stand with Videssence Fluorescent Icelites, Apple ${ }^{\circledR}$ Macintosh $^{\circledR}$ G4 and G3, Gateway $^{\mathrm{TM}}$ workstation, DVD storage disks.

\section{Further reading}

Brown, Lloyd A. The Story of Maps. New York: Dover, 1977; orig. pub. 1949.

Harley, J. B. The New Nature of Map: Essays in the History of Cartography. Paul Laxton, ed. Baltimore: Johns Hopkins University Press, 200I.

Paullin, Charles O. Atlas of the Historical Geography of the United States. John K. Wright, ed.

Carnegie Institution of Washington Publication no. 4OI. Washington, D.C.: Carnegie Institution of Washington and American Geographical Society of New York, 1932.

Raisz, Erwin. General Cartography. 2d ed. New York: McGraw-Hill, 1948. 


\section{Further reading (continued)}

Reps, John William. Views and Viewmakers of Urban America: Lithographs of Towns and Cities in the United States and Canada, I834-1926. Columbia, Mo.: University of Missouri Press, 1984.

Robinson, Arthur H. Early Thematic Mapping in the History of Cartography. Chicago: University of Chicago Press, 1982.

Short, John R. Representing the Republic: Mapping the United States I600-1900. London: Reaktion Books, 200I.

Snyder, John P. Flattening the Earth: Two Thousand Years of Map Projections. Chicago: University of Chicago Press, 1993.

Woodward, David, and others, eds. History of Cartography, multiple volumes. Chicago: University of Chicago Press, beginning 1987.

Online resources

David Rumsey Historical Map Collection: www.davidrumsey.com

Electronic Cultural Atlas Initiative Metadata Clearinghouse: ecai.org/tech/mdch.html

ESRI Geography Network: www.geographynetwork.com

Library of Congress Memory Web site: memory.loc.gov/ammem/gmdhtml/gmdhome.html

\section{Notes}

I. Over the course of history, maps have been produced in many other media: static and mobile; written and oral; in two, three, and four dimensions.

2. To hold the detail in historical maps, 600 pixels per inch are often required. Because highresolution scans result in very large raster files, frequently over one gigabyte, image compression is required to ease the transmission of files and their incorporation into GIS.

3. John Corrigan and Tracy Neal Leavelle, Catholic Missions in Colonial North America (Berkeley, Calif.: California Digital Library for the Electronic Cultural Atlas Initiative, forthcoming).

4. Map scale is the ratio of a distance on a map to the corresponding distance on the ground. The larger the ratio, the smaller the scale. A small-scale map of the world might have a ratio of I:5,000,000, while a large-scale city map might have a ratio of $\mathrm{I}: 25,000$.

5. Daniel Dorling and David Fairbairn, Mapping: Ways of Representing the World (Dorchester, Dorset: Addison Wesley Longman Limited, 1997), 28-38.

6. In order to best represent topography, we used a vertical exaggeration factor of I.5 when displaying Chevalier's San Francisco map and Wheeler's Yosemite Valley map in 3-D. The 3-D bathymetry map of San Francisco was created using a vertical exaggeration factor of 7 . Since this exaggeration is applied equally to the entire surface, the relationship between depths or heights in a particular landscape remain proportional.

7. In a TIN, a form of the tesseral model, the vertices of the non-overlapping triangles used to represent a surface are irregularly spaced nodes. Each node has an x,y coordinate and a surface, or z, value. Unlike a grid, a TIN allows dense information in complex areas and sparse information in simpler or more homogeneous areas, a characteristic that makes it suitable for modeling highly variable surfaces such as the chasms and plains of the seafloor. 